\title{
STAINING OF TOXOPLASMA IN HISTOLOGICAL SECTIONS*
}

BY

\author{
CHARLES SMITH \\ Department of Pathology, Institute of Ophthalmology, University of London.
}

EXTRACELLULAR toxoplasma, although present in abundance in smears from animals infected experimentally, can only occasionally be found in sections from suspected toxoplasma lesions. In the eye, Wilder (1952a, b) has described organisms morphologically indistinguishable from toxoplasma in cases of granulomatous uveitis, but even in these sections the organisms were not numerous and were found only after a careful search.

Pinkerton and Weinman (1940) stated that Giemsa's was the most satisfactory stain for these organisms, but it is not suitable for use on celloidin sections of the eye, and a search has been made for a more useful stain for demonstrating these parasites. The need for such a stain was further emphasized by the occurrence of lesions associated with serological evidence of toxoplasmosis in which the organisms could not be demonstrated.

\section{Methods}

Smears from experimental animals showed large numbers of extracellular toxoplasma, but when these smears were stained with haematoxylin and eosin the organisms were comparatively difficult to find, as they stained irregularly with haematoxylin. Other stains were therefore investigated in sections of experimental lesions in chick embryos, and it was found that Heidenhrain's iron haematoxylin was most satisfactory for demonstrating the extracellular forms.

\section{Technique}

Place sections in distilled water in 5 per cent. ferric alum for $2 \mathrm{hrs}$ at $37^{\circ} \mathrm{C}$. Rinse rapidly and stain in Heidenhain's haematoxylin for $2 \mathrm{hrs}$ at $37^{\circ} \mathrm{C}$. Differentiate with 1 per cent. ferric alum until suitably stained.

The organisms stain black and the crescentic shape makes the toxoplasma readily recognizable. In serial sections from experimental lesions it was possible to identify many more parasites in sections stained by this technique than in those stained by haematoxylin and eosin.

Difficulties may be encountered with Heidenhain's iron haematoxylin in highly cellular tissues in that the intensity of stain may obscure the organisms. In such cases Weigert's iron haematoxylin may be used. This stains both parasites and tissues less intensely, and the organisms are more rapidly differentiated.

\footnotetext{
* Received for publication March 19, 1953.
} 
The accompanying photomicrograph shows the extracellular forms in sections of the chorio-allantoic membrane of a chick embryo, stained by Heidenhain's iron haematoxylin.

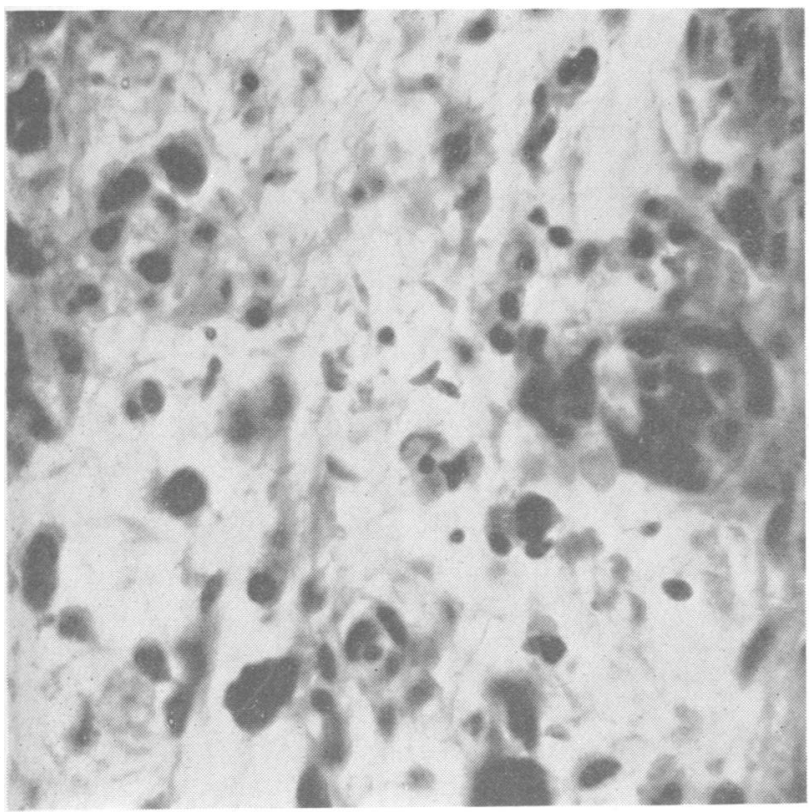

FIGURE. - Section of chorioallantoic membrane of chick embryo stained by iron haematoxylin to show extracellular toxoplasma. 850 .

\section{Summary}

The present techniques for staining toxoplasma are unsatisfactory and are particularly unsuitable for the identification of the organisms in celloidin sections. It has been found that iron haematoxylin stains the extracellular forms intensely, and the method is reported in the hope that it will be of use in studying granulomatous uveitis.

I should like to thank Mr. A. McNeil for his technical assistance.

\section{REFERENCES}

Pinkerton, H., and Weinman, D. (1940). Arch. Path., Chicago, 30, 374. WILDER, H. C. (1952a). Arch. Ophthal., 47, 425. (1952b). Ibid., 48, 127. 